\title{
Innovation Performance in EU and Slovakia
}

\author{
Miroslava Barbušová ${ }^{1}$, L'uboslav Dulina ${ }^{1}$, Eleonóra Bigošová ${ }^{1}$, \\ Iveta Rolinčinová ${ }^{1}$ \\ ${ }_{1}$ University of Žilina, Faculty of Mechanical Engineering, Department of Industrial \\ Engineering \\ Univerzitná 8215/1, 01026 Žilina, Slovakia \\ miroslava.barbusova@fstroj.uniza.sk \\ luboslav.dulina@fstroj.uniza.sk \\ eleonora.bigosova@fstroj.uniza.sk \\ iveta.rolincinova@fstroj.uniza.sk
}

\begin{abstract}
Annotation: The article focuses on the innovative results of the European Union and Slovakia and their subsequent comparison. In developed economies, innovation is the main driver of achieving the competitiveness of society as well as countries. Achieving the economic development of society and countries requires radical innovations that change habits and have an impact on job creation and regional development. This article helps improve tracking of innovation performance issues.
\end{abstract}

\section{Introduction}

Performance is an economic category that is linked to a systemic view of it is measurement and evaluation. The system whose performance is to be measured and evaluated corresponds to its internal structure. In practice, we encounter both the performance of the economy of the national economy as well as the financial performance of the company, the performance of employees, the quality management system, organization or business processes, and various other economic categories. [1]

Enterprises with innovative activity are those that:

- $\quad$ launched new or significantly improved products;

- $\quad$ introduce new or significantly improved processes within the company;

- introduce organizational or marketing innovations;

- have incomplete or suspended innovation activities.

\subsection{Performance and structure of the economy}

GDP per capita in purchasing power standards is a measure for interpreting real income differences between countries. Higher income can increase the demand for new innovative goods and services. Economic growth is captured by the average annual growth rate of GDP for 2017-2019. In economies that grow faster, increasing demand may provide more favourable conditions for enterprises to sell their goods and services. [2] 
Differences in economic structures are important. In particular, differences in the share of manufacturing industry in GDP, and in the so-called high-tech activities in manufacturing and services, are important factors that explain why countries can perform better or worse on indicators like business R\&D expenditures, PCT patents, and innovative enterprises. Medium-high and high-tech industries have higher technological intensities than other industries. [2]

These industries, on average, will have higher R\&D expenditures, more patent applications, and higher shares of innovating enterprises. Countries with above average shares of these industries are expected to perform better on several EIS indicators. For example, for the EU27 on average, $85 \%$ of R\&D expenditures in manufacturing are accounted for by medium-high and high-technology manufacturing industries. Also, the share of enterprises that introduced a product and/or process innovation is higher in medium-high and high-technology manufacturing industries compared to all core industries covered in the Community Innovation Survey. [2]

\section{Performance of EU Member States innovation systems}

Based on their average performance scores as calculated by a composite indicator, the Summary Innovation Index, Member States fall into four different performance groups. Denmark, Finland, Luxembourg, Netherlands, and Sweden are Innovation Leaders with innovation performance well above the EU average. Austria, Belgium, Estonia, France, Germany, Ireland, and Portugal are Strong Innovators with performance above or close to the EU average. The performance of Croatia, Cyprus, Czechia, Greece, Hungary, Italy, Latvia, Lithuania, Malta, Poland, Slovakia, Slovenia, and Spain is below the EU average. These countries are Moderate Innovators. Bulgaria and Romania are Modest Innovators with performance well below the EU average. [3]

The EIS measurement framework distinguishes between four main types of activities, capturing ten innovation dimensions and in total 27 different indicators. Framework conditions capture the main drivers of innovation performance external to the firm and cover three innovation dimensions: Human resources, Attractive research systems, as well as Innovation-friendly environment. Investments capture public and private investment in research and innovation and cover two dimensions: Finance and support and Firm investments. Innovation activities capture the innovation efforts at the level of the firm, grouped in three innovation dimensions: Innovators, Linkages, and Intellectual assets. Impacts cover the effects of firm's innovation activities in two innovation dimensions: Employment impacts and Sales impacts. [2]

The performance of EU national innovation systems is measured by the Summary Innovation Index, which is a composite indicator obtained by taking an unweighted average of the 27 indicators. 
Figure 1 shows the scores for the Summary Innovation Index for all EU Member States in 2019, i.e. the most recent year, 2018, and the reference year 2012. Based on this year's results, the Member States fall into four performance groups:

- $\quad$ The first group of Innovation Leaders includes 5 Member States where performance is above $125 \%$ of the EU average. The Innovation Leaders are Denmark, Finland, Luxembourg, the Netherlands, and Sweden.

- $\quad$ The second group of Strong Innovators includes 7 Member States with a performance between $95 \%$ and $125 \%$ of the EU average. Austria, Belgium, Estonia, France, Germany, Ireland, and Portugal are Strong Innovators.

- The third group of Moderate Innovators includes 13 Member States where performance is between $50 \%$ and $95 \%$ of the EU average. Croatia, Cyprus, Czechia, Greece, Hungary, Italy, Latvia, Lithuania, Malta, Poland, Slovakia, Slovenia, and Spain belong to this group.

- The fourth group of Modest Innovators includes two Member States that show a performance level below $50 \%$ of the EU average. This group includes Bulgaria and Romania. [2]

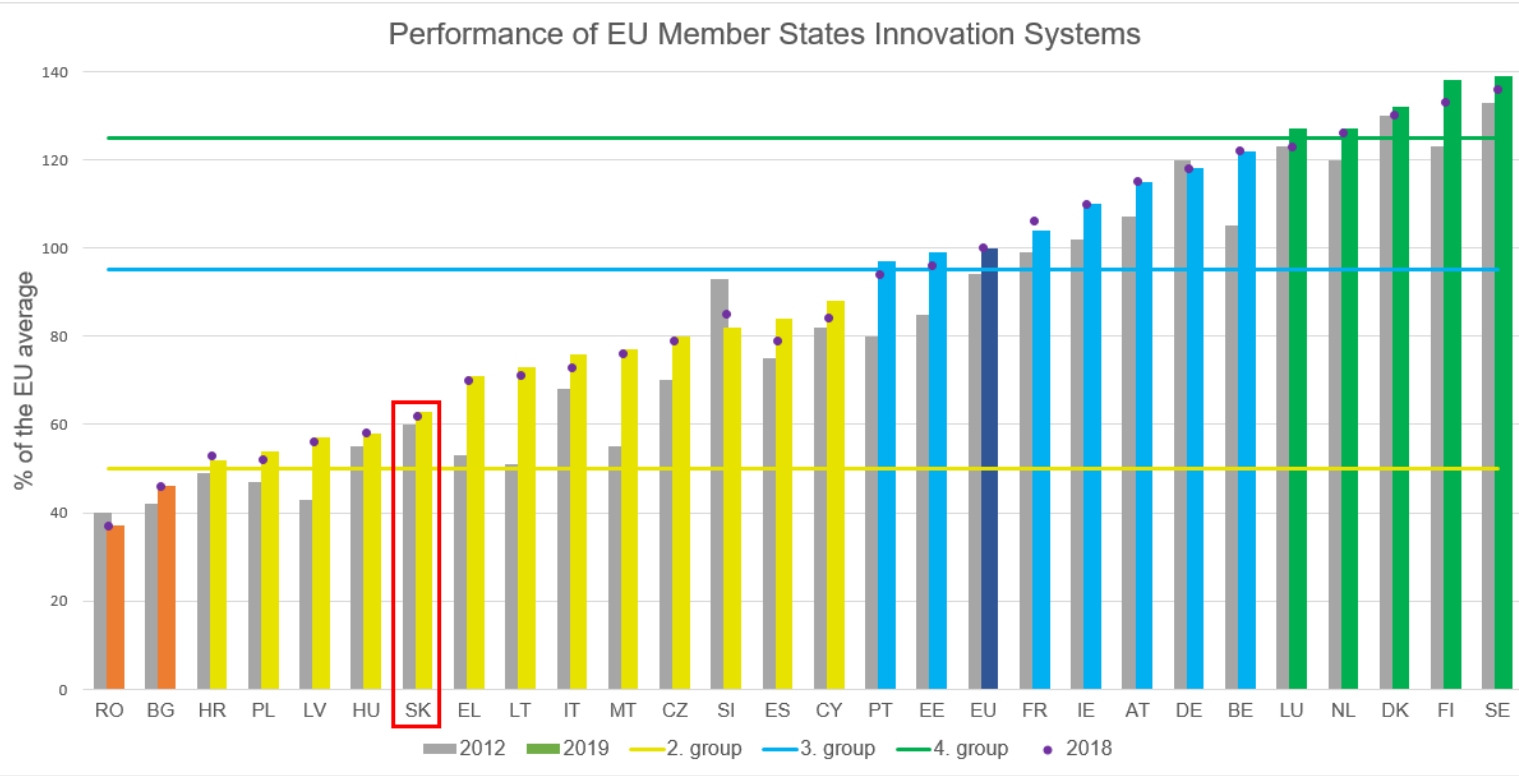

Figure 1 - Performance of EU Member STates Innovation System [2]

\subsection{Comparison of Changes in the Performance of EU Member States}

This section discusses performance changes over time for each of the innovation performance groups and the Member States included in each of the groups. For the EU, performance between 2012 and 2019 improved by 8.9 percentage points. Performance improved for 24 Member States and worsened for three Member States (fig. 2). The vertical axis shows the 
change in performance between 2012 and 2019 relative to that of the EU in 2012. The horizontal axis shows Member States performance in 2019.

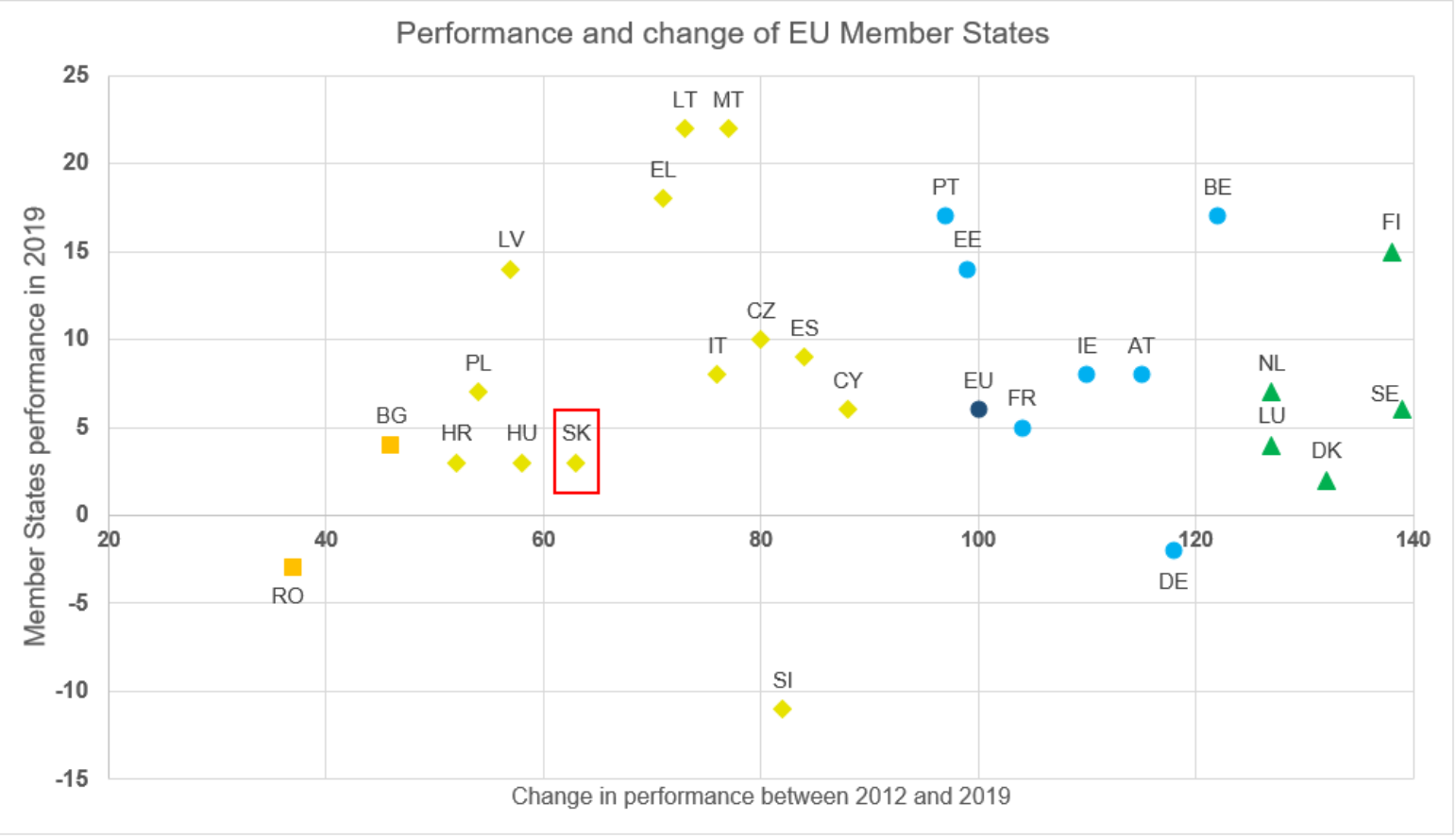

Figure 2 - Performance and change of EU Member States [author]

In past years, less innovative countries tended to improve their performance faster than more innovative countries; there was a negative link between the level of and the change in performance. Between 2012 and 2017, there has been a moderate rate of convergence in innovation performance between Member States, with lower performing countries, on average improving their level of innovation performance at a higher rate than higher performing countries. This process of convergence has accelerated in 2018 and 2019. Compared to 2018, performance in 2019 has improved for 25 Member States, most notably for Cyprus, Spain, and Finland, and performance has declined for two Member States, Slovenia, and France.

\section{Innovation dimensions}

Performance of the EU innovation system, measured as the weighted average of the performance of the innovation systems of all 27 Member States, has improved by 8.9 percentage points between 2012 and 2019 . However, there are differences in performance changes for the different dimensions and indicators.

The order of performance groups observed for the Summary Innovation Index also applies to most dimensions. The Innovation Leaders perform best in eight dimensions, with the Strong Innovators showing highest performance in Innovators and Sales Impacts (Fig. 3). In several innovation dimensions, performance differences vary considerably between the performance groups. The performance difference between the Innovation Leaders and the Strong 
Innovators in Innovation-Friendly Environment is almost $79 \%$-points; in Attractive Research Systems and Human Resources it is close to $50 \%$-points. Performance differences between the Innovation Leaders and the Strong Innovators are relatively small in Firm investments, Sales Impacts and Innovators. Between the Strong and Moderate Innovators, performance differences are high (more than 50\%-points) for Innovators, Linkages and Finance and Support, and performance differences are relatively small for Innovationfriendly Environment and Employment impacts. Between the Moderate and Modest Innovators, performance differences are relatively high (more than 50\%-points) for Firm Investments, Innovators and Human resources, and performance differences are relatively small for Intellectual assets and Employment impacts. [2]

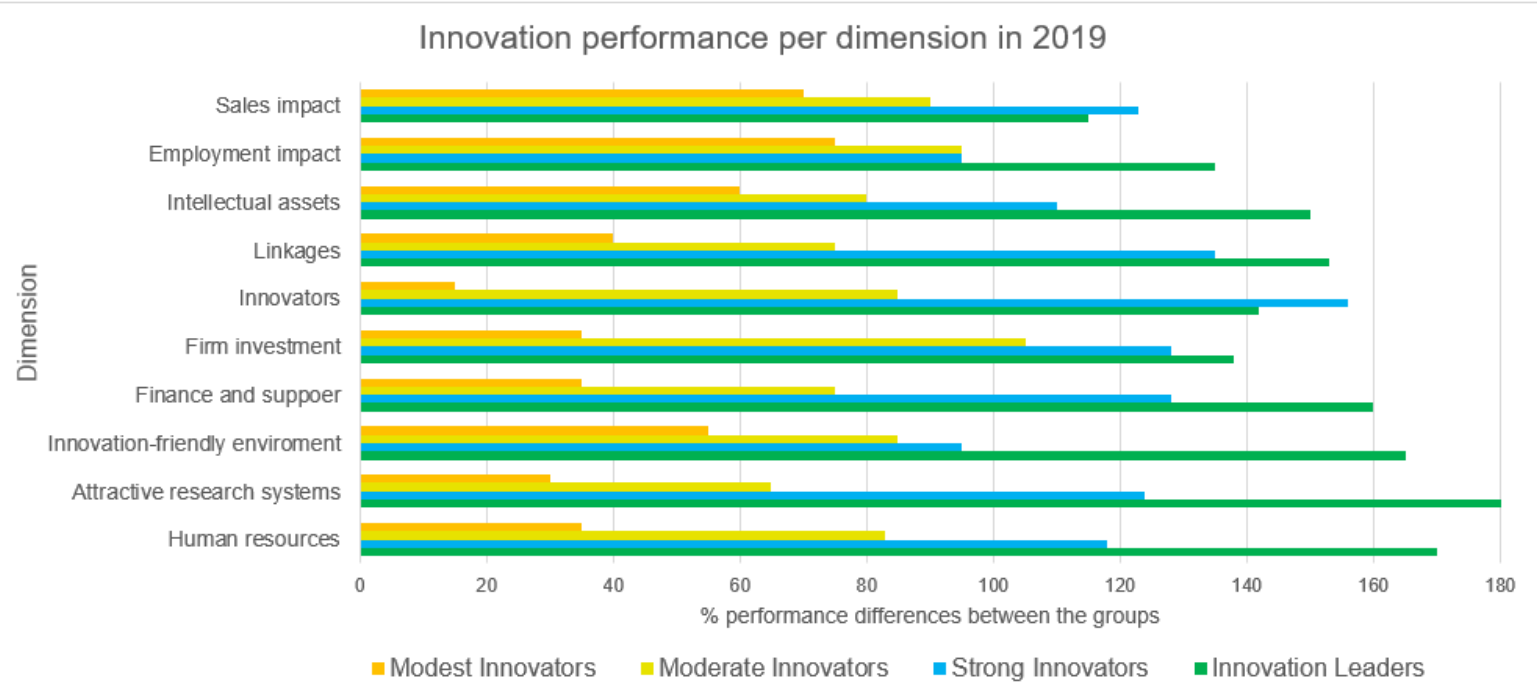

Figure 3 - Innovation performance per dimension in 2019 [2]

\section{$4 \quad$ Innovation performance in Slovakia}

Slovakia is a Moderate Innovator. Over time, performance has increased relative to that of the EU in 2012. Employment impacts and Sales impacts are the strongest innovation dimensions, with Slovakia performing above the EU average. Slovakia scores particularly well on Employment in fast-growing enterprises of innovative sectors, Sales of new-to-market and new-to-firm product innovations, Medium and high-tech product exports, and New doctorate graduates. Finance and support, Innovators and Intellectual assets are the weakest innovation dimensions. Overall, Slovakia's lowest indicator scores include Venture capital expenditures, $R \& D$ expenditures in the business sector, Lifelong learning, and Opportunity-driven entrepreneurship. Structural differences with the EU are shown in the table below. Slovakia shows the highest positive difference to the EU in Total Entrepreneurial Activity, Value-added share foreign-controlled enterprises and Average annual change in GDP, and the biggest negative difference in Top R\&D spending enterprises, GDP per capita and Buyer sophistication. [4] 
Table 1 - Comparison performance and structure of the economy between EU and Slovakia [4]

\begin{tabular}{|l|c|c|}
\hline \multicolumn{3}{|c|}{ Performance and structure of the economy } \\
\hline GDP per capita (PPS) & SK & EU \\
\hline Avarege annual GDP growth (\%) & 21,800 & 29,100 \\
\hline Employment share manufacturing (NACE C) (\%) & 3.13 & 1.84 \\
\hline of which High and medium high-tech (\%) & 24.6 & 16.6 \\
\hline Employment share services (NACE G-N) (\%) & 45.2 & 37.5 \\
\hline \multicolumn{1}{|c|}{ of which knowledge-intensive services (\%) } & 29.1 & 41.4 \\
\hline Turnover share SMEs (\%) & 35.2 & 34.3 \\
\hline Turnover share large enterprises (\%) & 42.8 & 43.3 \\
\hline $\begin{array}{l}\text { Foreign-controlled enterprises - share of value } \\
\text { added (\%) }\end{array}$ & 19.9 & 11.1 \\
\hline
\end{tabular}

The table 1 shows that GDP per capita in the Slovak Republic is lower than the average value of GDP per capita in the EU, but the average annual GDP growth is higher in Slovakia. The employment share manufacturing is higher in Slovakia than in the European Union and thus also in high and medium high-tech companies.

Table 2 - Comparison business and entrepreneurship between EU and Slovakia [4]

\begin{tabular}{|c|c|c|}
\hline \multicolumn{3}{|c|}{ Business and entrepreneurship } \\
\hline \multicolumn{2}{|c|}{ SK } & EU \\
\hline Enterprise births (10+ employees) (\%) & 1.6 & 1.1 \\
\hline Total Entrepreneurial Activity (TEA) (\%) & 12.4 & 6.7 \\
\hline FDI net inflows (\% GDP) & n/a & 2.6 \\
\hline $\begin{array}{c}\text { Top R\&D spending enterprises per 10 milion } \\
\text { population }\end{array}$ & 0.0 & 16.2 \\
\hline Buyer sophistication (1 to 7 best) & 3.0 & 3.7 \\
\hline
\end{tabular}

In table 2 we can see that, the Enterprise births in Slovakia is $0.5 \%$ higher than in the EU. The total entrepreneurial activity in Slovakia is up to $5.7 \%$ higher than the EU average. 


\subsection{Factors limiting innovation performance}

According to [5], in the period $2016-201830.7 \%$ of enterprises in industry and selected services were innovatively active. However, even in these companies, they encountered problems that did not allow them to engage in further innovation. The main factors limiting innovation activities can be found in Fig. 4. The most serious factor is the lack of funding sources. [5]

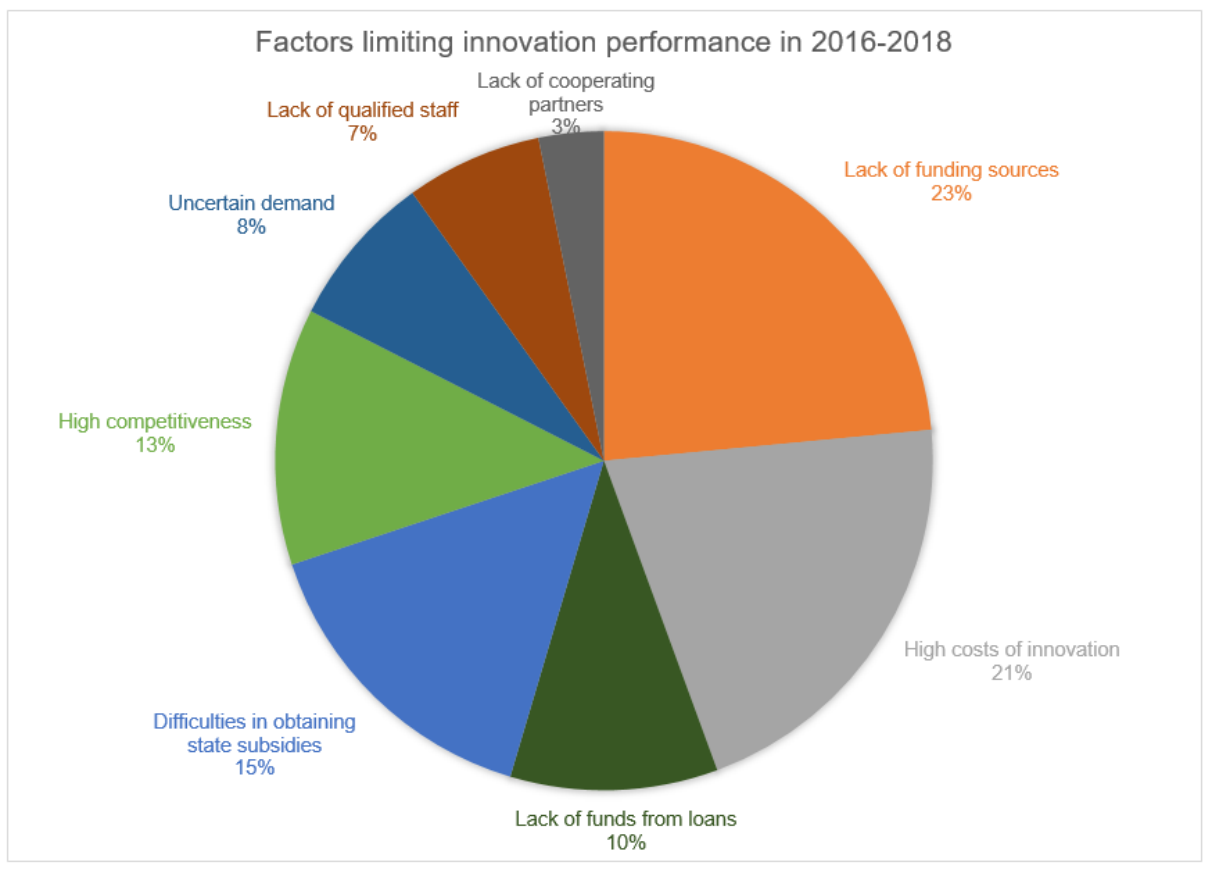

Figure 4 - Factors limiting innovation performance in 2016-2018 [5]

\section{Conclusion}

Slovakia's innovation performance is below the EU average in most of the monitored indicators. Relative strengths lie in the number of new doctorate graduates and the population with a tertiary education. Employment fast-growing enterprises is also above the EU average. Exports of medium and high technology products are also above the EU average. Innovation performance in the Slovak Republic in comparison with the economies of other European countries is lower and does not bring the expected positive result in the form of increased competitiveness of Slovak companies. Slovakia has a demonstrable innovation potential, but its growth must be stimulated and supported. There are several small and medium-sized, fast-growing companies with the potential to become a leader in a certain area of business, in which many new ideas emerge. However, without effective support, these are difficult to transform into new products, patents, competitive advantages or jobs.

\section{Acknowledgments}

This work was supported by the Slovak Research and Development Agency under the Contract no. APVV-14-0752. 


\section{References}

[1] GRZNÁR P., GREGOR M. Research into the possibilities of improving business processes. Central European Institute of Technology, 2008.

[2] European Innovation Scoreboard 2020. Publications Office of the European Union: Luxembourg, 2020. ISBN 987-92-76-16366-4.

[3] Innovation Strategy on Slovakia in 2014-2020. [online]. [cit. 23. 8. 2020]. Accessed from:

https://lt.justice.gov.sk/Attachment/Vlastn\%C3\%BD\%20materi\%C3\%A1I doc.pdf?instEID=1\&attEID=51522\&docEID=287000\&matEID=5788\&langEID $=1 \& \mathrm{tStamp}=2013010$

[4] FUSKO. M., BUČKOVÁ, M. Digital models for auxiliary and service processes. In: InvEnt 2018, Žilina, Slovakia, 2018. ISBN 978-80-89865-08-6.

[5] Overview of Innovation Results for 2019. [online]. [cit. 23. 8. 2020]. Accessed from:

https://ec.europa.eu/regional policy/sk/newsroom/news/2019/06/17-062019-2019-innovation-scoreboards-the-innovation-performance-of-the-euand-its-regions-is-increasing 